\title{
Sphingosine-1-Phosphate Phosphatase 2
}

National Cancer Institute

\section{Source}

National Cancer Institute. Sphingosine-1-Phosphate Phosphatase 2. NCI Thesaurus.

Code C105047.

Sphingosine-1-phosphate phosphatase 2 (399 aa, $\sim 48 \mathrm{kDa}$ ) is encoded by the human SGPP2 gene. This protein plays a role in regulating intracellular and extracellular sphing osine-1-phosphate levels. 